\title{
Peripheral Administration of Antisense Oligonucleotides Targeting the Amyloid- $\beta$ Protein Precursor Reverses A $\beta$ PP and LRP-1 Overexpression in the Aged SAMP8 Mouse Brain
}

\author{
Michelle A. Erickson ${ }^{\mathrm{a}, \mathrm{b}}$, Michael L. Niehoff ${ }^{\mathrm{c}, \mathrm{d}}$, Susan A. Farr ${ }^{\mathrm{c}, \mathrm{d}}$, John E. Morley ${ }^{\mathrm{c}, \mathrm{d}}$, Lucy A. Dillman ${ }^{\mathrm{a}}$, \\ Kristin M. Lynch ${ }^{\mathrm{a}}$ and William A. Banks ${ }^{\mathrm{a}, *}$ \\ ${ }^{a}$ GRECC, Veterans Affairs Puget Sound Health Care System and University of Washington School of Medicine, \\ Division of Gerontology and Geriatric Medicine, Department of Internal Medicine, Seattle, WA, USA \\ ${ }^{\mathrm{b}}$ Saint Louis University, Department of Pharmacology and Physiology, St. Louis, MO, USA \\ ${ }^{\mathrm{c}}$ Veterans Affairs Medical Center-St. Louis, St. Louis, MO, USA \\ ${ }^{\mathrm{d}}$ Saint Louis University School of Medicine, Division of Geriatrics, Department of Internal Medicine, St. Louis, \\ MO, USA
}

Handling Associate Editor: D. Allan Butterfield

Accepted 4 November 2011

\begin{abstract}
The senescence accelerated mouse-prone 8 (SAMP8) mouse model of Alzheimer's disease has a natural mutation leading to age-related increases in the amyloid- $\beta$ protein precursor $(\mathrm{A} \beta \mathrm{PP})$ and amyloid- $\beta(\mathrm{A} \beta)$ in the brain, memory impairment, and deficits in $A \beta$ removal from the brain. Previous studies show that centrally administered antisense oligonucleotide directed against $A \beta P P$ can decrease $A \beta P P$ expression and $A \beta$ production in the brains of aged SAMP8 mice, and improve memory. The same antisense crosses the blood-brain barrier and reverses memory deficits when injected intravenously. Here, we give $6 \mu \mathrm{g}$ of A $\beta P P$ or control antisense 3 times over 2 week intervals to 12 month old SAMP8 mice. Object recognition test was done 48 hours later, followed by removal of whole brains for immunoblot analysis of A $\beta P P$, low-density lipoprotein-related protein- 1 (LRP-1), p-glycoprotein (Pgp), receptor for advanced glycation endproducts (RAGE), or ELISA of soluble A $\beta_{40}$. Our results show that A $\beta P P$ antisense completely reverses a 30\% age-associated increase in A $\beta P P$ signal $(p<0.05$ versus untreated 4 month old SAMP8). Soluble $A \beta_{40}$ increased with age, but was not reversed by antisense. LRP-1 large and small subunits increased significantly with age $(147.7 \%, p<0.01$ and $123.7 \%, p<0.05$ respectively), and A $\beta P P$ antisense completely reversed these increases $(p<0.05)$. Pgp and RAGE were not significantly altered with age or antisense. Antisense also caused improvements in memory $(p<0.001)$. Together, these data support the therapeutic potential of A $\beta P P$ antisense and show a unique association between A $\beta$ PP and LRP-1 expression in the SAMP8 mouse.
\end{abstract}

${ }^{*}$ Correspondence to: William A. Banks, Bldg. 1, Rm. 810A, 1660 Columbian Way, Seattle, WA 98108, USA. Tel.: +1 206764 2701; Fax: +1 206764 2569; E-mail: bankswa@ slu.edu. 
Keywords: Abcb1, amyloid- $\beta$ peptides, amyloid- $\beta$ protein precursor, antisense, blood-brain barrier, LRP1, oligonucleotides, Pgp, RAGE, SAMP8

Supplementary data available online: http://dx.doi.org/10.3233/JAD-2011-111517

\section{INTRODUCTION}

A common difficulty in development of central nervous system (CNS) therapeutics is promoting their access to the brain. Due to the presence of the bloodbrain barrier (BBB), the chemical nature of drugs to treat CNS disease is generally limited to small, non-polar molecules which can diffuse across cell membranes [1]. Given that the BBB is also a dynamic regulatory interface for bidirectional peptide transport $[2,3]$, there is much interest in utilizing these transport systems for drug delivery to the brain. Previously, our lab and others have used phosphorothioated antisense oligonucleotides to modify protein expression in vivo [4-7]. We have also demonstrated that these antisense oligonucleotides have a saturable BBB transport system which allows them to access the CNS and alter expression of their protein targets $[5,8,9]$. Therefore, in addition to their use in studying protein function in vivo, antisense also shows potential as a therapeutic for CNS disease.

One example of the therapeutic value of antisense oligonucleotide involves studies done in the SAMP8 mouse model. This mouse strain arose from a spontaneous mutation which results in a phenotype of accelerated aging [10], age-associated increases in brain levels of A $\beta P P$ and $A \beta$ [11-13] as well as impairments in learning and memory [14]. Therefore, the SAMP8 mouse has been studied as a model for Alzheimer's disease (AD) [15]. We have previously shown that intracerebroventricular (ICV) administration of phosphorothioated antisense oligonucleotide directed against A $\beta P P$ in aged SAMP8 mice results in decreased levels of $A \beta P P$ and $A \beta$ in brain and reverses deficits in learning and memory [6]. The same antisense can cross the BBB when administered peripherally and exerts similar behavioral effects as ICV antisense [8]. The latter two findings demonstrate the potential of A $\beta P P$ antisense as a possible treatment for $\mathrm{AD}$, and warrant further investigation of neurochemical changes in reference to pathways resulting in $A \beta$ accumulation in the brain.

In addition to $A \beta$ accumulation, the SAMP8 mouse also develops deficits in $A \beta$ transport across the $\mathrm{BBB}$ with age [16]. According to the neurovascular hypothesis of $\mathrm{AD}$ [17], this finding suggests that
BBB impairment in this model promotes $A \beta$ accumulation in the CNS and likely contributes to its $\mathrm{AD}$ phenotype. Three predominant transporters have been identified at the BBB which play important roles in $\mathrm{A} \beta$ transport and have been implicated in AD. These are low-density lipoprotein-related protein-1 (LRP-1), p-glycoprotein (Pgp), and receptor for advanced glycation endproducts (RAGE) [18, 19]. LRP-1 mediates the brain-to-blood transport (efflux) of $\mathrm{A} \beta$ [20] and plays a major role in $A \beta$ clearance from the brain [21]. Alterations in brain levels of LRP-1 have been observed in normal aging and $\mathrm{AD}$, and these alterations depend on cell type. Immunoblots using midfrontal cortex homogenates of $\mathrm{AD}$ individuals versus age-matched controls demonstrated that total LRP-1 expression in brain gradually decreases with age, and is downregulated to an even greater extent in AD [22]. Another study showed that increased oxidative modifications to LRP-1 were observed in AD hippocampus when compared to age-matched controls [23]. Immunohistochemical studies elucidated that LRP-1 is downregulated in the microvasculature of AD frontal cortex, and that microvascular LRP-1 expression was inversely correlated with degree of $A \beta$ immunoreactivity [20]. A subsequent study found that in hippocampi from aged non-AD individuals, strong staining of LRP-1 was evident in the microvasculature, whereas neurons were weakly stained. This pattern was found to be reversed in $\mathrm{AD}$ [24]. Interestingly, evidence supports that through an interaction with A $\beta P P$, LRP-1 enhances amyloidogenic A $\beta P$ processing [25]. Together, these findings suggest that changes in LRP-1 observed in AD favor increased $\mathrm{A} \beta$ production and decreased $\mathrm{A} \beta$ clearance from the brain. RAGE has been shown to participate in blood-to-brain transport (influx) of $A \beta$ [26], and is upregulated in brain microvessels with age [27, 28]. Therefore, circulating $A \beta$ can contribute to the $A \beta$ pool in brain, and may also contribute to changes in CNS A $\beta$ observed in AD. Interestingly, the same study by Donahue et al. showing opposing changes in LRP-1 in neurons versus vasculature found that in addition to increased microvascular RAGE expression in $\mathrm{AD}$, neuronal expression of RAGE was decreased compared to age-matched controls. This finding suggests that expression of LRP-1 and RAGE might 
be inversely coupled both in normal aging and $\mathrm{AD}$. Pgp is a multi-drug transporter of the ATP-binding cassette family, whose primary function is to restrict circulating components from entering the brain [29]. Pgp has also been identified to play a role in $A \beta$ transport, both by increasing efflux [30, 31] and restricting influx [32] of A $\beta$. Downregulation of Pgp has been demonstrated in $\mathrm{AD}$ brain microvasculature compared to age-matched controls [33], suggesting that a Pgp deficiency may also contribute to $A \beta$ accumulation in $\mathrm{AD}$. Given the association of changes in all three proteins in $\mathrm{AD}$, and the defect in $\mathrm{BBB}$ transport of $A \beta$ in the SAMP8 model, an important question is whether expression of these transporters are altered in SAMP8 mice with age. Recently, we have shown that the $A \beta$ efflux deficit in the aged SAMP8 mouse is reversed with A $\beta P P$ antisense [34], suggesting that $\mathrm{A} \beta \mathrm{PP} / \mathrm{A} \beta$ pathology in this model may play a role in the regulation of $A \beta$ transport out of the brain. Therefore, it is also possible that $A \beta$ itself plays a role in the regulation of its transport in and out of the brain.

In this study, our first goal was to determine whether peripherally administered A $\beta P P$ antisense reverses pathological increases in $A \beta P P$ and $A \beta$ in the brains of aged SAMP8 mice. Our second goal was to determine whether altered expression of the $A \beta$ transporters LRP-1, Pgp, and RAGE were associated with alterations in $A \beta P P / A \beta$ due to age and antisense in the SAMP8 model. Our findings were 1) that peripherally administered A $\beta P P$ antisense is effective in reversing age-associated A $\beta P P$ increases in SAMP8 mouse brains, but does not reduce total soluble $A \beta_{40}$, and 2) that LRP-1 follows a similar pattern of expression as $\mathrm{A} \beta \mathrm{PP}$ with age and antisense in this model.

\section{MATERIALS AND METHODS}

\section{Animal use}

All animal protocols were performed in an AALCC (International Association for Assessment and Accreditation) accredited facility and approved by the animal committee of the VA and St Louis University Medical Centers. SAMP8 mice from in-house colonies were kept on a 12/12 hour light/dark cycle with food and water freely available.

\section{Antisense regimens}

Phosphorothioate oligodeoxynucleotide antisense directed at $\mathrm{A} \beta_{17-30}\left(5^{\prime}-(\mathrm{P}=\mathrm{S}) \mathrm{GGCGCCTTTGTTCG}\right.$ AACCCACATCTTCAGCAAAGAACACCAG-3') or a random antisense sequence $\left(5^{\prime}-(\mathrm{P}=\mathrm{S})\right.$ GATCA CGTACACATCGACACCAGTCGCCATGACTGAG CTT-3') was synthesized by the Midland Certified Reagent Company (Midland, TX). Male 12 month only SAMP8 mice were given 3 tail vein injections of $6 \mu \mathrm{g}$ A $\beta P P$ or control antisense ( $n=10$ per group) suspended in $0.2 \mathrm{ml}$ normal saline at 2 week intervals, followed by behavioral studies at $48 \mathrm{~h}$ or two weeks after the final injection. Mice from the 48-h group were anesthetized with $0.15 \mathrm{ml} 40 \%$ urethane $24 \mathrm{~h}$ later ( $72 \mathrm{~h}$ after the final antisense injection) and the upper circulatory system was perfused with Lactated Ringer's solution to clear blood from the vascular space. Whole brains (cerebrum and cerebellum) were harvested, cut in half along the sagittal suture, and each half snap-frozen and stored at $-70^{\circ} \mathrm{C}$ immediately following removal. As an additional control, brains from 4 month old untreated SAMP8 mice $(n=10)$ were identically harvested for comparison.

\section{Behavioral assessment}

Memory assessment was conducted using the object recognition test as previously described [5]. This method tests hippocampal-dependent memory [35] and was chosen over other behavioral tests because it is low-stress and reveals similar cognitive impairments as those observed in AD [36-39]. Prior to testing, mice were habituated for three consecutive days to the testing apparatus (a $58 \times 66 \times 11 \mathrm{~cm}$ white, plastic box). During habituation, each mouse was allowed to freely explore the testing apparatus for $5 \mathrm{~min}$. On the first day of training, mice were placed in the testing apparatus for $5 \mathrm{~min}$ and allowed to explore a pair of identical objects (objects A and B; both were $7 \times 6.3 \times 5.1 \mathrm{~cm}$ ). On the second day of training, one of the original objects was replaced with a new, or novel, object (Object C; $8.2 \times 3.8 \times 7.4 \mathrm{~cm}$ ). Mice were placed in the testing apparatus for $5 \mathrm{~min}$ and the amount of time each mouse spent sniffing or touching of the novel object was recorded. Results were expressed as the percent of time spent investigating the novel object.

\section{Protein extraction from brains}

Protein extraction for immunoblot analysis was done by adding a $10 \mathrm{x}$ volume of extraction buffer (20 mM Tris-HCl, 0.15 M NaCl, 2 mM EDTA, 1\% Triton X-100, $1 \mathrm{mM}$ PMSF, Protease Inhibitor cocktail) to each hemibrain, and homogenizing using a Tissue Tearor (Cole-Parmer) homogenizer. Homogenates were shaken at $4^{\circ} \mathrm{C}$ for $30 \mathrm{~min}$ and then centrifuged 
twice at 20,000 g to pellet debris. Protein estimates on supernatants were done using a BCA assay (Pierce). Protein extraction for measurement of $\mathrm{A} \beta_{40}$ was done using the same protocol in extraction buffer containing $0.2 \%$ Triton $\mathrm{X}-100$, which extracts soluble extracellular and intracellular $\mathrm{A} \beta$ [40].

\section{Immunoblotting and densitometric analysis for ABPP, LRP-1, Pgp, and RAGE}

Prior to analyte measurement in SAMP8 brain homogenates, all experimental conditions were optimized for each antibody to ensure protein loading amounts were within the linear range of signal. The A $\beta P P$ and LRP-1 antibodies were also validated for their antigen specificity using either knockout brain tissue (A $\beta$ PP; a generous donation from the lab of Dr. David Cook), or knockout cell lines (LRP-1; MEF-1 and PEA-13 cell lines, ATCC). For measurement of $\mathrm{A} \beta \mathrm{PP}, 15 \mu \mathrm{g}$ of denatured and reduced brain protein extract was run on a $4-12 \%$ Bis-tris gel (Invitrogen). For measurement of LRP-1, $15 \mu \mathrm{g}$ of denatured brain protein extract was run on a 3-8\% Tris-acetate gel (Invitrogen). For measurement of Pgp, $15 \mu \mathrm{g}$ of denatured brain protein extract was run on a $4-12 \%$ Bis-tris gel (Invitrogen), and for measurement of RAGE, $25 \mu \mathrm{g}$ of denatured and reduced brain extract was run on a 4-12\% Bis-tris gel. Proteins from all gels were then transferred onto nitrocellulose membranes for $8 \mathrm{~min}$ at $20 \mathrm{~V}$ using an iBlot transfer device (Invitrogen). Portions of the membrane not containing the antigen of interest were either SYPRO stained [41] (Invitrogen) or blocked with $5 \%$ milk/PBS-T and probed for $\beta$-tubulin (Epitomics, $1 \mu \mathrm{g} / \mathrm{ml}$ in 5\% milk, $1 \mathrm{~h}$ room temperature (RT)) to confirm even loading. Portions of the membrane containing the antigens of interest were blocked with either 5\% milk/PBS-T (AßPP, LRP-1, Pgp) or $5 \% \mathrm{BSA} / \mathrm{PBS}-\mathrm{T}$ for $1 \mathrm{~h}$ RT and probed for the following: 1) N-terminal LRP-1 subunit (Sigma, $2 \mu \mathrm{g} / \mathrm{ml}$ $5 \%$ milk/PBS-T $1 \mathrm{~h} \mathrm{RT);} \mathrm{2)} \mathrm{C-terminal} \mathrm{LRP-1} \mathrm{sub-}$ unit (Epitomics, $0.1 \mu \mathrm{g} / \mathrm{ml}$ 5\% milk/PBS-T 1 h RT); 3) A $\beta P P$ (Epitomics, $1 \mu \mathrm{g} / \mathrm{ml}$ 5\% milk/PBS-T 1 h RT); 4) Pgp (Calbiochem, $3 \mu \mathrm{g} / \mathrm{ml} 5 \%$ milk/PBS-T overnight $4^{\circ} \mathrm{C}$ ); or 5) RAGE (Thermo Scientific, $2 \mu \mathrm{g} / \mathrm{ml} 5 \%$ BSA/PBS-T overnight $4^{\circ} \mathrm{C}$ ). Membranes were then washed and incubated with anti-rabbit (LRP-1, A $\beta P P$, Tubulin, RAGE) or anti-mouse (Pgp) secondary antibodies (Santa Cruz, 1:5000 1h RT), then washed again. Bands were visualized using SuperSignal West Pico chemiluminescent reagents (Thermo Scientific) and images (including SYPRO signal) captured on an ImageQuant LAS 4000 CCD camera (GE Health- care). Densitometric analysis was done using IQTL software (GE Healthcare). For analysis of SYPRO signal, bands which were detectable across all lanes were quantified, and the sum of signal from each lane was used to normalize the protein signal of interest. This method of normalization was used because housekeeping proteins either changed with treatment, or did not produce linear signal within the range of protein loading amounts under the conditions specified and therefore were unsuitable.

\section{Quantification of $A \beta_{40}$}

Colorimetric high-sensitivity kits from WAKO were used to quantify $A \beta_{40}$ in our extracts. Samples were diluted $1: 3$ in standard diluent provided with the kit, and standards were diluted in buffer resembling sample matrix. Samples were then measured for $A \beta_{40}$ according to kit instructions. We have extensively tested this kit for reliable quantification of $\mathrm{A} \beta$ levels, and have found that signal is linear over a wide range of brain tissue dilutions, spike recovery is approximately $100 \%$, and signal is specific as demonstrated by lack of signal in A $\beta$ PP knockout brain tissue (unpublished results). Others have also found that $A \beta$ levels measured by Western blot correlate with $A \beta$ levels measured using this kit [42].

\section{Statistical analysis}

All data were analyzed using GraphPad Prism 5 software. The number of mice used in each study is indicated, with error bars representing the standard error of the mean (SEM). Student's $t$-test was used for

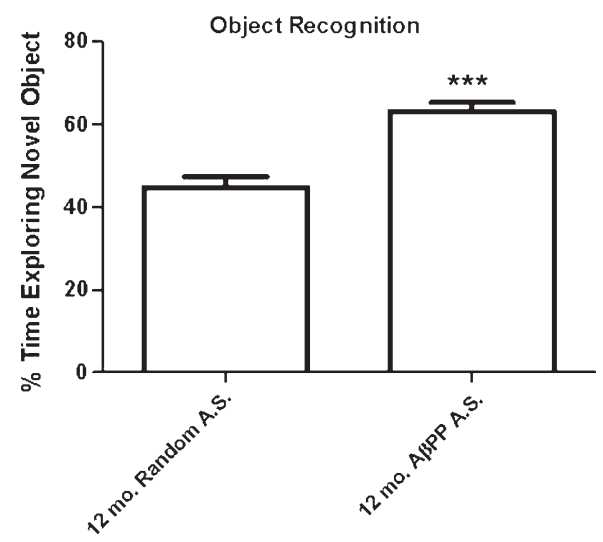

Fig. 1. Object recognition test performance of 12 month old SAMP8 mice $48 \mathrm{~h}$ following a regimen of peripherally administered A $\beta P P$ antisense or random control antisense. Data analyzed by Student's $t$-test $(n=10, * * * p<0.001)$. 
comparison of two groups. More than two groups were compared by analysis of variance (ANOVA) followed by Newman-Keuls multiple comparisons test.

\section{RESULTS}

Assessment of memory following systemic administration of $A \beta P P$ antisense

$48 \mathrm{~h}$ after the last injection of the antisense treatment regimen, 12 month old SAMP8 mice were tested for hippocampal-dependent memory based on their ability to recognize a novel object [35]. Figure 1 shows that peripherally administered $A \beta P P$ antisense improves performance in the object recognition test. There was no difference in the total amount of time spent exploring the objects on either the acquisition or the retention phase of the test. The mean time in seconds spent exploring the objects during acquisition was $25.36 \pm 3.36$ for random antisense and $23.80 \pm 2.97$ for A $\beta P P$ antisense. Because previous studies have examined effects of A $\beta P P$ antisense 2 weeks after the last injection, a second group of mice was tested for learning and memory 2 weeks after an antisense treatment regimen. In this group, a similar albeit less robust trend was found for A $\beta P P$ antisense (data not shown). Therefore, all studies of protein expression were performed on the 48-h antisense group.

\section{Effects of antisense on $A \beta P P$ and $A \beta_{40}$ expression} and on $A \beta$ transport proteins

Following antisense treatment and behavioral assessment, protein expression of A $\beta$ PP, LRP-1,
RAGE, and Pgp was measured. Preliminary immunoblot studies were carried out using brain tissue extracts to optimize experimental conditions for each antibody, testing signal linearity over a range of protein concentrations (supplementary Figure 1; available online: http://www.j-alz.com/issues/28/vol28-4.html\# supplementarydata10). Importantly, A $\beta P P$ signal was found to saturate at loading amounts higher than $25 \mu \mathrm{g}$, and Pgp signal was linear up to $25 \mu \mathrm{g}$, but paradoxically decreased at a loading amount of $50 \mu \mathrm{g}$. Therefore, caution was taken to ensure that the amount of protein loaded for each immunoblot produced signal within the linear range of detection. The LRP-1 and A $\beta P P$ antibodies were tested for antigen specificity in knockout tissue, and no immunoreactive bands were observed in knockouts (supplementary Figure 2). $\mathrm{A} \beta \mathrm{PP}$ antisense treatment reversed the age-associated increase of A $\beta P P$ expression to levels comparable to 4 month old SAMP8 mice (Fig. 2a and b). Levels of soluble $A \beta_{40}$ increased with age in the SAMP8 mice, but this was not reversed by antisense (Fig. 2c). We were unable to measure $A \beta_{42}$ in our samples, as levels were either below the detectable range of commercially available assays which can measure murine $A \beta$, or commercially available kits claiming enhanced sensitivity did not show specificity for $A \beta$ (unpublished findings). Immunoblot analysis showed that SAMP8 mice have an age-dependent increase in both the large and small subunits of LRP-1, and that A $\beta P P$ antisense reverses this increase in LRP-1 expression (Fig. 3). No significant changes in RAGE were found with age or antisense treatment (Fig. 4a and b). Pgp showed a trend towards an increase with age in the SAMP8 mouse (Fig. $4 \mathrm{c}$ and d), although this
A

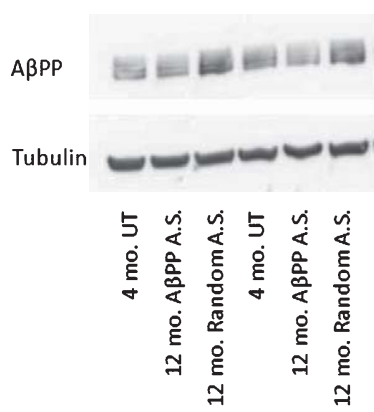

B

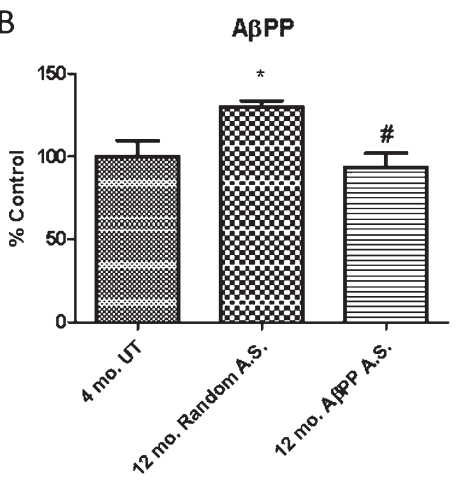

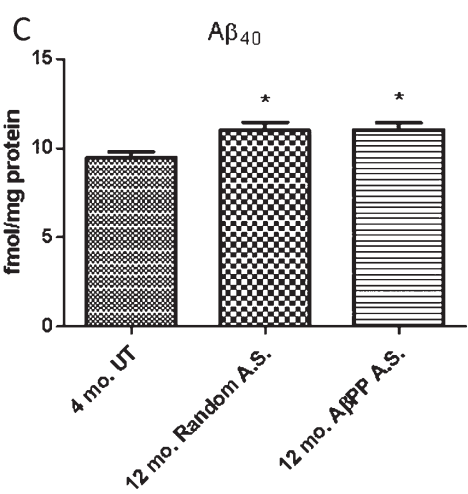

Fig. 2. A $\beta P P$ and soluble $A \beta_{40}$ protein levels in untreated 4 month old and antisense treated 12 month old SAMP8 mouse brains. A) Representative immunoblot of A $\beta$ PP. B) Densitometric analysis of A $\beta P P$ band intensities normalized to $\beta$-tubulin $(n=6$ per group). C) Quantification of soluble $\mathrm{A} \beta_{40}$ by ELISA ( $n=8-10$ per group). All data analyzed by one way ANOVA and Newman-Keuls multiple comparisons test, $* p<0.05$ compared to 4 month old UT, ${ }^{\#} p<0.05$ compared to 12 month old Random. 
A

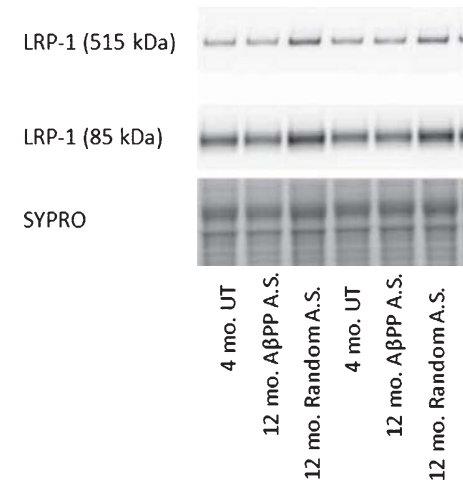

B

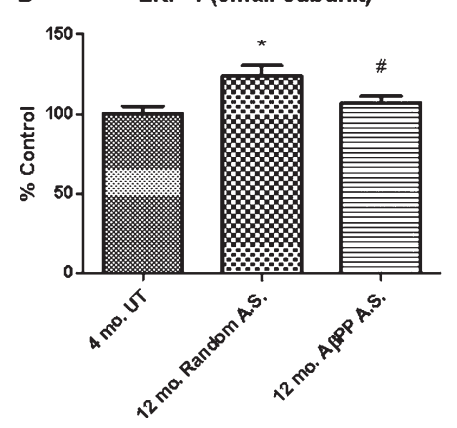

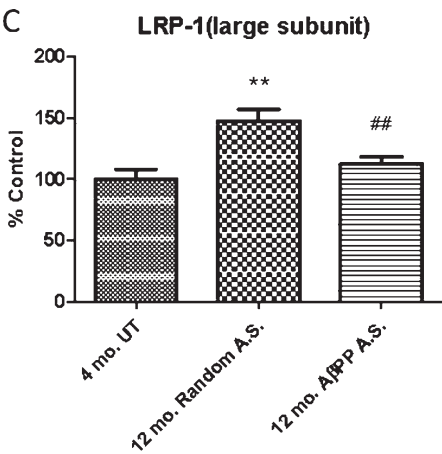

Fig. 3. Protein levels of LRP-1 in untreated 4 month old and antisense treated 12 month old SAMP8 mouse brains. A) Representative immunoblots of LRP-1 large and small subunits. B, C) Densitometric analysis of small and large subunits respectively, band intensities normalized to SYPRO stain ( $n=6$ per group). All data analyzed by one way ANOVA and Newman-Keuls multiple comparisons test, ${ }^{*} p<0.05, * * p<0.01$ compared to 4 month old UT, ${ }^{\#} p<0.05,{ }^{\# \#} p<0.01$ compared to 12 month old Random.

was not significant due to the high variability of Pgp expression in all samples. To confirm that this trend was not due to Pgp levels in some samples exceeding the linear range of detection, immunoblotting of Pgp was repeated using $5 \mu \mathrm{g}$ of sample instead of 15 . This second blot produced a similar trend in Pgp expression of these samples (data not shown) and therefore the source of variability observed is likely biological.

\section{DISCUSSION}

In this study, we have shown for the first time that peripheral administration of antisense which specifically targets A $\beta$ PP reduces its expression in SAMP8 mouse brains. This was associated with improved performance in the object recognition test, which is a low-stress assessment of hippocampal-dependent memory [35-37]. Individuals with AD also have deficiency in recognizing novel objects, supporting that this test may reveal analogous impairments in murine models [38, 39]. Improvement of cognitive defects in aged SAMP8 mice highlights the therapeutic potential of antisense in AD. This particular antisense molecule has been well-characterized for its ability to cross the BBB by a saturable mechanism, suggesting that a specific transport system exists which facilitates its entry into the brain [43]. Furthermore, this study by Banks et al. showed that uptake of this molecule was highest in hippocampus, one of the predominant brain regions affected in AD. Although the transport system for antisense has not yet been identified, this latter finding suggests that an increased density of this transporter is also present in hippocampus, offering the advantage of selective delivery to this region.

Results from this study agree well with previous findings that both $A \beta P P$ and $A \beta$ increase with age in SAMP8 mice [6]. We did not, however, find that A $\beta P P$ antisense also reduces brain levels of $A \beta$. Although this does raise the question of whether $A \beta P P$ itself plays a role in memory impairment in this model, the complexity of $A \beta$ biology and methodology may also explain this finding. It has been extensively shown that the method used for $A \beta$ extraction from brain is reflective of its cellular compartmentalization and aggregation state [40, 44]. Our goal in this study was to measure soluble forms of $A \beta$, as these (monomeric forms, in particular) are available for transport across the BBB or for cellular uptake [45]. For this reason, our extraction method enriched for soluble forms of $A \beta$ present in both intra- and extracellular compartments. This extraction method may not detect redistribution of compartmentalization and/or aggregation state of $A \beta$ which likely occur following decreases in its production. Given that aggregation status [46-48] as well as cellular localization [49] in the brain are both important in dictating $A \beta$ neurotoxicity, a redistribution of $A \beta$ pools could explain improvement of learning and memory in this model. Because we only measured $A \beta_{40}$ in our samples, we also cannot rule out the possibility that soluble $A \beta_{42}$ levels are decreased by antisense. $A \beta_{42}$ is more prone to aggregation and oligomer formation [50-52], and therefore likely plays an important role in age-associated pathology in the SAMP8 model. This highlights the importance of 
A
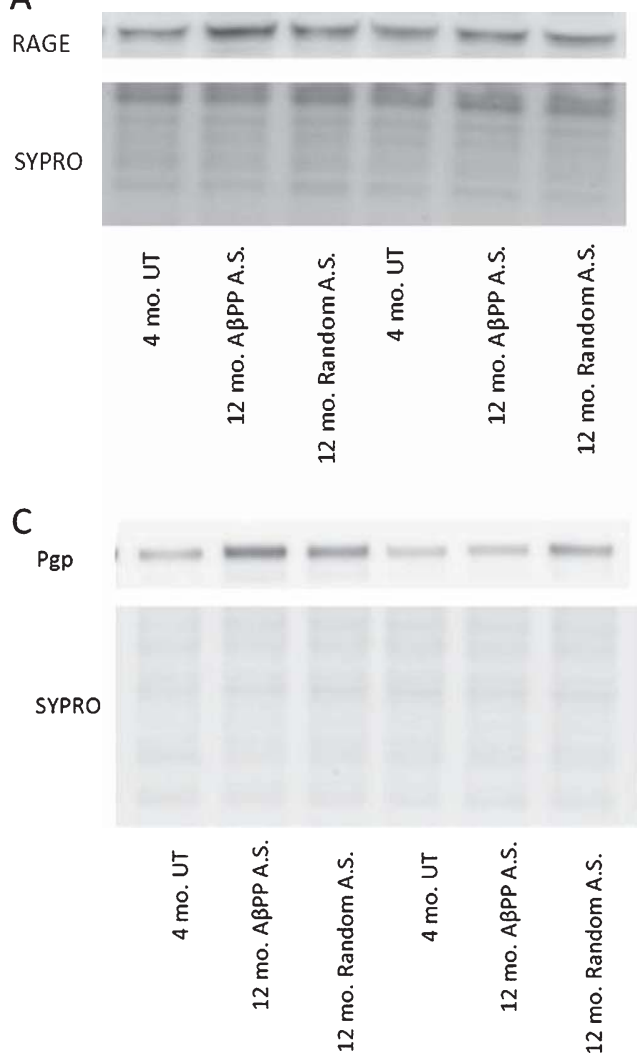

B

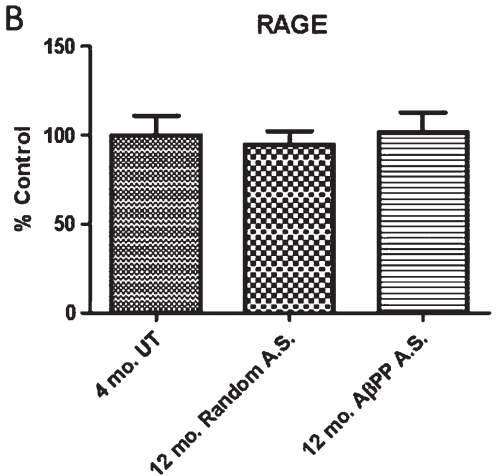

D

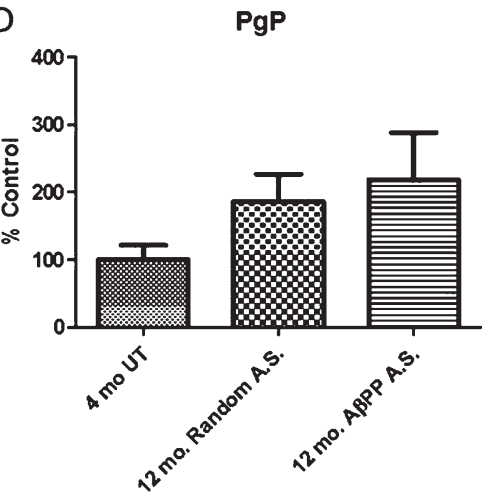

Fig. 4. Protein levels of Pgp and RAGE in untreated 4 month old and antisense treated 12 month oldSAMP8 mouse brains. A, C) Representative immunoblots of Pgp and RAGE respectively. B, D) Densitometric analysis of Pgp and RAGE respectively, band intensities normalized to SYPRO stain ( $n=6$ per group). All data analyzed by one way ANOVA and Newman-Keuls multiple comparisons test.

developing a highly sensitive and specific assay to measure the murine form of $A \beta_{42}$ that is compatible with a variety of extraction methods. Future studies correlating cognitive function to soluble versus total pools of $A \beta$ over a time curve following $A \beta P P$ antisense administration would provide much information on $A \beta$ biology as well as therapeutic mechanisms of A $\beta P P$ antisense.

In addition to A $\beta P P$, LRP-1 was also found to be overexpressed with aging in brains of SAMP8 mice, and this increase was reversed by A $\beta P P$ antisense. Although we did find a trend toward an increase in Pgp expression with age which agrees with a previous report from another group [53], we found no significant changes in Pgp or RAGE following A $\beta P P$ antisense administration. This indicates that $\mathrm{A} \beta P P$ may play a unique role in the regulation of LRP-1 expression. LRP-1 can bind KPI domains of A $\beta P P$ on its N-terminus [54], and can also interact with its C-terminus via the adaptor protein Fe65 [55, 56]. The latter interaction has been shown to increase $\mathrm{A} \beta \mathrm{PP}$ endocytosis, which increases the amount of $\mathrm{A} \beta \mathrm{PP}$ available for BACE cleavage and promotes production of $A \beta[57,58]$. Therefore, in addition to overexpression of A $\beta P P$, increased expression of LRP- 1 which is observed with age in the SAMP8 mouse could contribute to increased A $\beta$ load. LRP-1 has also been implicated in neuronal uptake of $A \beta$ [59]. Because intraneuronal $A \beta$ can be toxic through a variety of mechanisms [49], increased LRP-1 in neuronal tissue in the SAMP8 mouse could play an important role in its age-related pathology. Interestingly, total LRP-1 levels has been found to decrease in both mild cognitive impairment [60] and in AD [22]. Immunohistochemical studies have found that LRP-1 stains predominantly in the microvasculature compared to neurons in aged non-AD individuals, and that expression patterns are reversed in AD, such that predominant LRP-1 expression is in neurons [24] and LRP-1 is downregulated in the brain microvasculature [20, 24]. Furthermore, increases of neuronal $\mathrm{A} \beta$ are an early sign of $\mathrm{AD}[61$, 62] and LRP-1 has been shown to mediate neuronal 
$A \beta$ uptake [59]. Therefore, a pattern of LRP-1 upregulation in neurons and downregulation in the brain microvasculature would both contribute to $A \beta$ accumulation in the brain. The fact that we observed an increase in AßPP expression in the SAMP8 mouse may reflect a mechanistic difference in SAMP8 and human $\mathrm{AD}$ pathology, and/or a temporal mismatch in LRP-1 related changes in brain. One disadvantage to our study is that the use of whole brain homogenate does not provide information about changes in protein expression for specific cell types. However, given that the brain microvasculature makes up approximately $1 \%$ of brain tissue by weight, changes in microvascular LRP-1 may be masked by abundant LRP-1 expression in other brain cell types, such as neurons [63]. Therefore, it is possible that LRP-1 expression patterns in the SAMP8 mouse mimic immunohistochemical findings for $\mathrm{AD}$, but that these changes are masked. This may also explain why we did not observe significant changes in total RAGE, even though its expression patterns are also altered in $\mathrm{AD}$ and normal aging [27, $28,30,64]$. Future studies investigating both regional and cell-type specific changes in both $\mathrm{A} \beta \mathrm{PP}$ and $\mathrm{A} \beta$ transporter expression would provide useful information both on the mechanism of $A \beta$ accumulation in the aged SAMP8 mouse brain, and how well observed changes match pathological findings in AD.

Antisense reversal of LRP-1 overexpression further demonstrates that $\mathrm{A} \beta \mathrm{PP}$ plays a regulatory role in LRP-1 expression. In a recent study, it has been shown that LRP-1 expression is increased in AßPP knockout mice due to the lack of transcriptional repression by AICD, an A $\beta P P$ cleavage product [65]. Although we observed an opposite trend for LRP-1/A $\beta P P$ expression, there are many differences in our study compared to that of Liu et al. which may explain this apparent conflict. First, A $\beta P P$ manipulation was done using antisense instead of gene deletion, and knockdown in our study resulted in restoration of A $\beta P P$ expression to physiological levels. Second, we compared LRP-1 levels in young and aged SAMP8 mice, whereas Liu et al. measured LRP-1 in newborn and 4 month old mice. Therefore, effects of aging, differences in mouse strain, and genetic manipulation could all contribute to conflicting results. Future studies investigating 1) AICD expression in the aged SAMP8 mouse, and 2) transcriptional regulation of LRP-1 by AICD when A $\beta$ PP expression is decreased with antisense would provide more information on how LRP-1/A 3 PP interactions affect each other in context of AD. Results from studies mentioned in the previous paragraph, however, do suggest that LRP-1 overexpression in neurons may be an early pathological event in AD. Therefore, this may be an additional mechanism by which A $\beta P P$ antisense exerts its therapeutic effects in the SAMP8 mouse.

In summary, we have shown that peripherally administered A $\beta P P$ antisense is effective in reducing expression of its target in brain. Our findings suggest, however, that the mechanism by which improvement of learning and memory occurs likely involves multiple systems which participate in $A \beta$ homeostasis within the brain. This highlights the possibility that novel AD therapeutics that target established pathways which reduce $A \beta$ toxicity and/or improve clearance in addition to reducing $A \beta$ production may show improved efficacy.

\section{ACKNOWLEDGMENTS}

This work was funded by VA Merit Review and the National Institutes of Health (AG029839).

Authors' disclosures available online (http://www.jalz.com/disclosures/view.php?id=1055).

\section{REFERENCES}

[1] Hossain S, Akaike T, Chowdhury EH (2010) Current approaches for drug delivery to central nervous system. Curr Drug Deliv 7, 389-397.

[2] Neuwelt EA, Bauer B, Fahlke C, Fricker G, Iadecola C, Janigro D, Leybaert L, Molnar Z, O’Donnell ME, Povlishock JT, Saunders NR, Sharp F, Stanimirovic D, Watts RJ, Drewes LR (2011) Engaging neuroscience to advance translational research in brain barrier biology. Nat Rev Neurosci 12, 169182.

[3] Ueno M, Nakagawa T, Wu B, Onodera M, Huang CL, Kusaka T, Araki N, Sakamoto H (2010) Transporters in the brain endothelial barrier. Curr Med Chem 17, 1125-1138.

[4] Zalachoras I, Evers MM, van Roon-Mom WM, Aartsma-Rus AM, Meijer OC (2011) Antisense-mediated RNA targeting: Versatile and expedient genetic manipulation in the brain. Front Mol Neurosci 4, 10.

[5] Jaeger LB, Dohgu S, Hwang MC, Farr SA, Murphy MP, Fleegal-DeMotta MA, Lynch JL, Robinson SM, Niehoff ML, Johnson SN, Kumar VB, Banks WA (2009) Testing the neurovascular hypothesis of Alzheimer's disease: LRP1 antisense reduces blood-brain barrier clearance, increases brain levels of amyloid-beta protein, and impairs cognition. $J$ Alzheimers Dis 17, 553-570.

[6] Kumar VB, Farr SA, Flood JF, Kamlesh V, Franko M, Banks WA, Morley JE (2000) Site-directed antisense oligonucleotide decreases the expression of amyloid precursor protein and reverses deficits in learning and memory in aged SAMP8 mice. Peptides 21, 1769-1775.

[7] Banks WA, Kumar VB, Morley JE (2004) Influence of ethanol dependence and methionine enkephalin antisense on serum endomorphin-1 and methionine enkephalin levels. Alcohol Clin Exp Res 28, 792-796.

[8] Banks WA, Farr SA, Butt W, Kumar VB, Franko MW, Morley JE (2001) Delivery across the blood-brain barrier of antisense directed against amyloid beta: Reversal of learning and mem- 
ory deficits in mice overexpressing amyloid precursor protein. J Pharmacol Exp Ther 297, 1113-1121.

[9] Banks WA, Jaeger LB, Urayama A, Kumar VB, Hileman SM, Gaskin FS, Llanza NV, Farr SA, Morley JE (2006) Preproenkephalin targeted antisenses cross the blood-brain barrier to reduce brain methionine enkephalin levels and increase voluntary ethanol drinking. Peptides 27, 784-796.

[10] Takeda T, Hosokawa M, Higuchi K (1997) Senescenceaccelerated mouse (SAM): A novel murine model of senescence. Exp Gerontol 32, 105-109.

[11] Nomura Y, Yamanaka Y, Kitamura Y, Arima T, Ohnuki T, Oomura Y, Sasaki K, Nagashima K, Ihara Y (1996) Senescence-accelerated mouse. Neurochemical studies on aging. Ann N Y Acad Sci 786, 410-418.

[12] Morley JE, Kumar VB, Bernardo AE, Farr SA, Uezu K, Tumosa N, Flood JF (2000) Beta-amyloid precursor polypeptide in SAMP8 mice affects learning and memory. Peptides 21, 1761-1767.

[13] Takemura M, Nakamura S, Akiguchi I, Ueno M, Oka N, Ishikawa S, Shimada A, Kimura J, Takeda T (1993) Beta/A4 proteinlike immunoreactive granular structures in the brain of senescence-accelerated mouse. Am J Pathol 142, 1887-1897.

[14] Flood JF, Morley JE (1998) Learning and memory in the SAMP8 mouse. Neurosci Biobehav Rev 22, 1-20.

[15] Pallas M, Camins A, Smith MA, Perry G, Lee HG, Casadesus G (2008) From aging to Alzheimer's disease: Unveiling "the switch" with the senescence-accelerated mouse model (SAMP8). J Alzheimers Dis 15, 615-624.

[16] Banks WA, Robinson SM, Verma S, Morley JE (2003) Efflux of human and mouse amyloid beta proteins 1-40 and 1-42 from brain: Impairment in a mouse model of Alzheimer's disease. Neuroscience 121, 487-492.

[17] Deane R, Zlokovic BV (2007) Role of the blood-brain barrier in the pathogenesis of Alzheimer's disease. Curr Alzheimer Res 4, 191-197.

[18] Deane R, Bell RD, Sagare A, Zlokovic BV (2009) Clearance of amyloid-beta peptide across the blood-brain barrier: Implication for therapies in Alzheimer's disease. CNS Neurol Disord Drug Targets 8, 16-30.

[19] Vogelgesang S, Jedlitschky G, Brenn A, Walker LC (2011) The role of the ABC transporter p-glycoprotein in the transport of beta-amyloid across the blood-brain barrier. Curr Pharm Des 17, 2778-2786.

[20] Shibata M, Yamada S, Kumar SR, Calero M, Bading J, Frangione B, Holtzman DM, Miller CA, Strickland DK, Ghiso J, Zlokovic BV (2000) Clearance of Alzheimer's amyloid-ss(140) peptide from brain by LDL receptor-related protein-1 at the blood-brain barrier. J Clin Invest 106, 1489-1499.

[21] Deane R, Wu Z, Zlokovic BV (2004) RAGE (yin) versus LRP (yang) balance regulates alzheimer amyloid beta-peptide clearance through transport across the blood-brain barrier. Stroke 35, 2628-2631.

[22] Kang DE, Pietrzik CU, Baum L, Chevallier N, Merriam DE, Kounnas MZ, Wagner SL, Troncoso JC, Kawas CH, Katzman R, Koo EH (2000) Modulation of amyloid beta-protein clearance and Alzheimer's disease susceptibility by the LDL receptor-related protein pathway. J Clin Invest 106, 11591166.

[23] Owen JB, Sultana R, Aluise CD, Erickson MA, Price TO, Bu G, Banks WA, Butterfield DA (2010) Oxidative modification to LDL receptor-related protein 1 in hippocampus from subjects with Alzheimer disease: Implications for Abeta accumulation in AD brain. Free Radic Biol Med 49, 1798-1803.

[24] Donahue JE, Flaherty SL, Johanson CE, Duncan JA, 3rd, Silverberg GD, Miller MC, Tavares R, Yang W, Wu Q, Sabo E,
Hovanesian V, Stopa EG (2006) RAGE, LRP-1, and amyloidbeta protein in Alzheimer's disease. Acta Neuropathol 112, 405-415.

[25] Pietrzik CU, Busse T, Merriam DE, Weggen S, Koo EH (2002) The cytoplasmic domain of the LDL receptor-related protein regulates multiple steps in APP processing. EMBO J 21, 56915700.

[26] Deane R, Du Yan S, Submamaryan RK, LaRue B, Jovanovic S, Hogg E, Welch D, Manness L, Lin C, Yu J, Zhu H, Ghiso J, Frangione B, Stern A, Schmidt AM, Armstrong DL, Arnold B, Liliensiek B, Nawroth P, Hofman F, Kindy M, Stern D, Zlokovic B (2003) RAGE mediates amyloid-beta peptide transport across the blood-brain barrier and accumulation in brain. Nat Med 9, 907-913.

[27] Yan SD, Chen X, Fu J, Chen M, Zhu H, Roher A, Slattery T, Zhao L, Nagashima M, Morser J, Migheli A, Nawroth P, Stern D, Schmidt AM (1996) RAGE and amyloid-beta peptide neurotoxicity in Alzheimer's disease. Nature 382, 685-691.

[28] Zlokovic BV (2008) New therapeutic targets in the neurovascular pathway in Alzheimer's disease. Neurotherapeutics $\mathbf{5}$, 409-414.

[29] Miller DS (2010) Regulation of P-glycoprotein and other ABC drug transporters at the blood-brain barrier. Trends Pharmacol Sci 31, 246-254.

[30] Cirrito JR, Deane R, Fagan AM, Spinner ML, Parsadanian M, Finn MB, Jiang H, Prior JL, Sagare A, Bales KR, Paul SM, Zlokovic BV, Piwnica-Worms D, Holtzman DM (2005) P-glycoprotein deficiency at the blood-brain barrier increases amyloid-beta deposition in an Alzheimer disease mouse model. J Clin Invest 115, 3285-3290.

[31] Hartz AM, Miller DS, Bauer B (2010) Restoring blood-brain barrier P-glycoprotein reduces brain amyloid-beta in a mouse model of Alzheimer's disease. Mol Pharmacol 77, 715-723.

[32] Candela P, Gosselet F, Saint-Pol J, Sevin E, Boucau MC, Boulanger E, Cecchelli R, Fenart L (2010) Apicalto-basolateral transport of amyloid-beta peptides through blood-brain barrier cells is mediated by the receptor for advanced glycation end-products and is restricted by P-glycoprotein. J Alzheimers Dis 22, 849-859.

[33] Wijesuriya HC, Bullock JY, Faull RL, Hladky SB, Barrand MA (2010) ABC efflux transporters in brain vasculature of Alzheimer's subjects. Brain Res 1358, 228-238.

[34] Banks WA, Kumar VB, Farr SA, Nakaoke R, Robinson SM, Morley JE (2011) Impairments in brain-to-blood transport of amyloid-beta and reabsorption of cerebrospinal fluid in an animal model of Alzheimer's disease are reversed by antisense directed against amyloid-beta protein precursor. J Alzheimers Dis 23, 599-605.

[35] Hammond RS, Tull LE, Stackman RW (2004) On the delay-dependent involvement of the hippocampus in object recognition memory. Neurobiol Learn Mem 82, 26-34.

[36] Harrison FE, Hosseini AH, McDonald MP (2009) Endogenous anxiety and stress responses in water maze and Barnes maze spatial memory tasks. Behav Brain Res 198, 247-251.

[37] Holscher C (1999) Stress impairs performance in spatial water maze learning tasks. Behav Brain Res 100, 225-235.

[38] Caterini F, Della Sala S, Spinnler H, Stangalino C, Tumbull $\mathrm{OH}$ (2002) Object recognition and object orientation in Alzheimer's disease. Neuropsychology 16, 146-155.

[39] Dennett HW, McKone E, Tavashmi R, Hall A, Pidcock M, Edwards M, Duchaine B (2011) The Cambridge Car Memory Test: A task matched in format to the Cambridge Face Memory Test, with norms, reliability, sex differences, dissociations from face memory, and expertise effects. Behav Res Methods. doi: 10.3758/s13428-011-0160-2. 
[40] Steinerman JR, Irizarry M, Scarmeas N, Raju S, Brandt J, Albert M, Blacker D, Hyman B, Stern Y (2008) Distinct pools of beta-amyloid in Alzheimer disease-affected brain: A clinicopathologic study. Arch Neurol 65, 906-912.

[41] Aldridge GM, Podrebarac DM, Greenough WT, Weiler IJ (2008) The use of total protein stains as loading controls: An alternative to high-abundance single-protein controls in semi-quantitative immunoblotting. J Neurosci Methods 172, 250-254.

[42] Silverberg GD, Miller MC, Messier AA, Majmudar S, Machan JT, Donahue JE, Stopa EG, Johanson CE (2010) Amyloid deposition and influx transporter expression at the blood-brain barrier increase in normal aging. $J$ Neuropathol Exp Neurol 69, 98-108.

[43] Banks WA, Farr SA, Butt W, Kumar VB, Franko MW, Morley JE (2001) Delivery across the blood-brain barrier of antisense directed against amyloid beta: Reversal of learning and memory deficits in mice overexpressing amyloid precursor protein. J Pharmacol Exp Ther 297, 1113-1121.

[44] Lesne S, Koh MT, Kotilinek L, Kayed R, Glabe CG, Yang A, Gallagher M, Ashe KH (2006) A specific amyloid-beta protein assembly in the brain impairs memory. Nature 440, 352-357.

[45] Deane R, Wu Z, Sagare A, Davis J, Du Yan S, Hamm K, Xu F, Parisi M, LaRue B, Hu HW, Spijkers P, Guo H, Song X, Lenting PJ, Van Nostrand WE, Zlokovic BV (2004) LRP/amyloid beta-peptide interaction mediates differential brain efflux of Abeta isoforms. Neuron 43, 333-344.

[46] Glabe CG (2008) Structural classification of toxic amyloid oligomers. J Biol Chem 283, 29639-29643.

[47] Klein WL, Krafft GA, Finch CE (2001) Targeting small Abeta oligomers: The solution to an Alzheimer's disease conundrum? Trends Neurosci 24, 219-224.

[48] Selkoe DJ (2002) Alzheimer's disease is a synaptic failure. Science 298, 789-791.

[49] Umeda T, Tomiyama T, Sakama N, Tanaka S, Lambert MP, Klein WL, Mori H (2011) Intraneuronal amyloid beta oligomers cause cell death via endoplasmic reticulum stress, endosomal/lysosomal leakage, and mitochondrial dysfunction in vivo. J Neurosci Res 89, 1031-1042.

[50] Klein WL, Stine WB Jr, Teplow DB (2004) Small assemblies of unmodified amyloid beta-protein are the proximate neurotoxin in Alzheimer's disease. Neurobiol Aging 25, 569-580.

[51] Yang M, Teplow DB (2008) Amyloid beta-protein monomer folding: Free-energy surfaces reveal alloform-specific differences. J Mol Biol 384, 450-464.

[52] Bernstein SL, Dupuis NF, Lazo ND, Wyttenbach T, Condron MM, Bitan G, Teplow DB, Shea JE, Ruotolo BT, Robinson CV, Bowers MT (2009) Amyloid-beta protein oligomerization and the importance of tetramers and dodecamers in the aetiology of Alzheimer's disease. Nat Chem $\mathbf{1}$, 326-331.

[53] Wu B, Ueno M, Onodera M, Kusaka T, Huang CL, Hosomi N, Kanenishi K, Sakamoto H (2009) Age-related changes in P-glycoprotein expression in senescence-accelerated mouse. Curr Aging Sci 2, 187-192.
[54] Kounnas MZ, Moir RD, Rebeck GW, Bush AI, Argraves WS, Tanzi RE, Hyman BT, Strickland DK (1995) LDL receptor-related protein, a multifunctional ApoE receptor, binds secreted beta-amyloid precursor protein and mediates its degradation. Cell 82, 331-340.

[55] Kinoshita A, Whelan CM, Smith CJ, Mikhailenko I, Rebeck GW, Strickland DK, Hyman BT (2001) Demonstration by fluorescence resonance energy transfer of two sites of interaction between the low-density lipoprotein receptor-related protein and the amyloid precursor protein: Role of the intracellular adapter protein Fe65. J Neurosci 21, 8354-8361.

[56] Pietrzik CU, Yoon IS, Jaeger S, Busse T, Weggen S, Koo EH (2004) FE65 constitutes the functional link between the lowdensity lipoprotein receptor-related protein and the amyloid precursor protein. J Neurosci 24, 4259-4265.

[57] Waldron E, Heilig C, Schweitzer A, Nadella N, Jaeger S, Martin AM, Weggen S, Brix K, Pietrzik CU (2008) LRP1 modulates APP trafficking along early compartments of the secretory pathway. Neurobiol Dis 31, 188-197.

[58] Yoon IS, Pietrzik CU, Kang DE, Koo EH (2005) Sequences from the low density lipoprotein receptor-related protein (LRP) cytoplasmic domain enhance amyloid beta protein production via the beta-secretase pathway without altering amyloid precursor protein/LRP nuclear signaling. J Biol Chem 280, 20140-20147.

[59] Fuentealba RA, Liu Q, Zhang J, Kanekiyo T, Hu X, Lee JM, LaDu MJ, Bu G (2010) Low-density lipoprotein receptorrelated protein 1 (LRP1) mediates neuronal Abeta42 uptake and lysosomal trafficking. PLoS One 5, e11884.

[60] Sultana R, Banks WA, Butterfield DA (2010) Decreased levels of PSD95 and two associated proteins and increased levels of $\mathrm{BCl} 2$ and caspase 3 in hippocampus from subjects with amnestic mild cognitive impairment: Insights into their potential roles for loss of synapses and memory, accumulation of Abeta, and neurodegeneration in a prodromal stage of Alzheimer's disease. J Neurosci Res 88, 469-477.

[61] Gouras GK, Tsai J, Naslund J, Vincent B, Edgar M, Checler F, Greenfield JP, Haroutunian V, Buxbaum JD, Xu H, Greengard P, Relkin NR (2000) Intraneuronal Abeta42 accumulation in human brain. Am J Pathol 156, 15-20.

[62] Fernandez-Vizarra P, Fernandez AP, Castro-Blanco S, Serrano J, Bentura ML, Martinez-Murillo R, Martinez A, Rodrigo J (2004) Intra- and extracellular Abeta and PHF in clinically evaluated cases of Alzheimer's disease. Histol Histopathol 19, 823-844.

[63] Lillis AP, Van Duyn LB, Murphy-Ullrich JE, Strickland DK (2008) LDL receptor-related protein 1: Unique tissue-specific functions revealed by selective gene knockout studies. Physiol Rev 88, 887-918.

[64] Miller MC, Tavares R, Johanson CE, Hovanesian V, Donahue JE, Gonzalez L, Silverberg GD, Stopa EG (2008) Hippocampal RAGE immunoreactivity in early and advanced Alzheimer's disease. Brain Res 1230, 273-280.

[65] Liu Q, Zerbinatti CV, Zhang J, Hoe HS, Wang B, Cole SL, Herz J, Muglia L, Bu G (2007) Amyloid precursor protein regulates brain apolipoprotein $\mathrm{E}$ and cholesterol metabolism through lipoprotein receptor LRP1. Neuron 56, 66-78. 